\title{
Contribution to the Discovery of a Novel Medicine for a Neuromuscular Disease and of other Promising Molecules for the Treatment of Neurodevelopmental and Neurodegenerative Diseases
}

\author{
Hasane Ratni*
}

SCS Senior Industrial Science Award 2020

\begin{abstract}
Nervous system disorders affect millions of people around the world, through a very broad range of diseases. Here we describe our contribution to find a treatment for patients suffering from three of those diseases. The first one, autism spectrum disorder (ASD), affects approximately one in every 59 children in US. The second one, spinal muscular atrophy (SMA) is a rare disease affecting 1 in 10000 live births worldwide, often leading to death if untreated. The third one, Alzheimer's disease (AD) is a very well known devastating disease with an estimated 50 million people living with $A D$ and other dementia, a number expected to triple by 2050 . Our strategy to address those diseases was directed towards the discovery of a selective vasopressin 1a (V1a) antagonist for ASD, a splicing modifier of the survival of motor neuron 2 (SMN2) for SMA, and finally a $\gamma$-secretase modulator (GSM) for AD. In the frame of our GSM project, we also reported the discovery of a bridge piperidine moiety as a bioisostere for a phenyl moiety with an improved drug-like profile.
\end{abstract}

Keywords: Enzymatic protein complex · GPCR $\cdot$ RNA $\cdot \gamma$-Secretase modulator (GSM) - Small molecules . Splicing modifier · SMN2 - Vasopressin 1a (V1a)

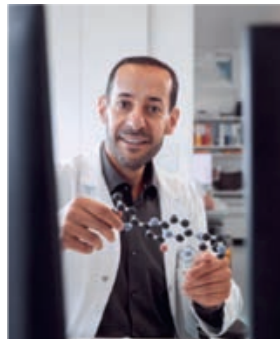

Hasane Ratni is a Distinguished Scientist, Medicinal Chemistry, at F. Hoffmann-La Roche Ltd., Basel, Switzerland. He successfully brought from early research to the clinic six molecules, one already successfully launched. He received his $\mathrm{PhD}$ at the University of Geneva (with E. P. Kündig) and did a post-doc at Tokyo University (with M. Shibasaki) before joining F. Hoffmann-La Roche Ltd in 2001. In 2005, he participated in a secondment within the Roche group at Chugai Pharmaceutical Co. Ltd, Gotemba Japan. His research has mainly been devoted to the areas of neuroscience (e.g. V1a receptor antagonist, in human clinical trials, phase 3 , for autism). He was the chemistry discovery project leader of the SMN program for the treatment of spinal muscular atrophy, and inventor of Risdiplam (Evrysdi) approved by FDA in August 2020 and EMA in March 2021. His current focus is on gamma secretase modulator for Alzheimer disease. He is an author or co-author of more than 120 patents and publications and received the following awards: In 2020: Senior Industrial Science Award by the Swiss Chemical Society (SCS) and the Roche CEO Award for Excellence (RMM). In 2019, the Paper of the year award by the Society of Toxicology (DDTSS), in 2016 the Gold medal at the Roche Patent Inventor's recognition event and in 2014 the Roche Leo Sternbach Award for Innovation in Chemistry.

\section{Introduction}

Nervous system disorders affects millions of people around the world, through a very broad range of diseases. Not surprisingly then, almost everyone knows someone affected by a neurological condition, which can have a profound impact on his or her day-to-day life. Those diseases cover an extremely broad range of incidence and prevalence as well as of patient ages, from newborn to elderly. Highlighting this diversity, we describe our contribution to find a treatment for well-known diseases such as autism spectrum disorder (ASD), Alzheimer's disease (AD) as well as a rare disease, spinal muscular atrophy (SMA) affecting newborns, children and adults.

We considered the use of a selective vasopressin 1a (V1a) antagonist for the potential treatment of ASD, which led to the discovery of two molecules, RO5028442 (1) ${ }^{[1]}$ and balovaptan (2) ${ }^{[2]}$, evaluated in clinic (Fig. 1). While compound $\mathbf{1}$ demonstrated a proof of concept in a phase 1 clinical trial, compound $\mathbf{2}$ progressed to phase 3 clinical trials. For the treatment of SMA, we focused on the identification of selective survival of motor neuron 2 (SMN2) gene splicing modifiers, which also led to two molecules evaluated in the clinic, RG7800 (3) ${ }^{[3]}$ and risdiplam (4) ${ }^{[4]}$ (Fig. 1), compound 4 ultimately being approved by the FDA in August 2020 and EMA in March 2021. Finally, our approach to tackle Alzheimer's disease relied on the discovery of $\gamma$-secretase modulators (GSM) leading to the discovery of RO7185876 (5) ${ }^{[5]}$ (Fig. 1) selected for entry into human enabling studies (GLP toxicology). 


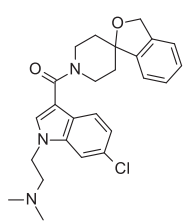

RO5028442; 1

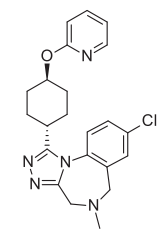

Balovaptan; 2

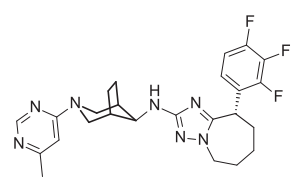

RO7185876; 5
$\mathrm{RG} 7800 ; 3$

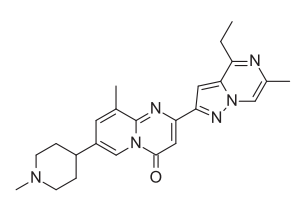

Risdiplam; 4

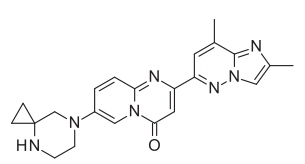

Fig. 1. Chemical structures of the V1a antagonists 1 and 2; the SMN2 splicing modifiers $\mathbf{3}$ and $\mathbf{4}$, and of the GSM compound $\mathbf{5}$.

In the frame of the GSM project, leading to the discovery of $\mathbf{5}$, we discovered that the bridge piperidine moiety was a suitable replacement of a phenyl moiety (Fig. 2), leading to a superior profile in terms of drug-like properties (solubility and lipophilicity). Additionally, a systematic match pair comparison between this bridge piperidine moiety with a phenyl and the recently reported saturated bioisosteres such as bicyclo[1,1,1]pentane (BCP) or bicyclo[2,2,2]octane (BCO) demonstrates its overall favorable profile. ${ }^{[6]}$

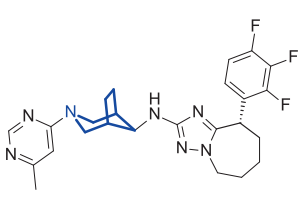

5

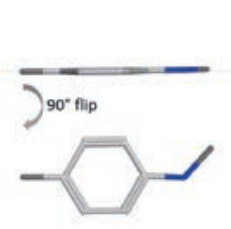

Phenyl

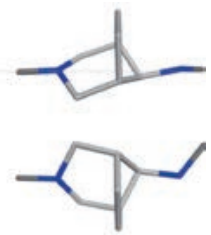

Bridge piperidine
Fig. 2. Bridge piperidine moiety as a superior phenyl moiety replacement.

In this article we report the research work done on the identification of the first brain penetrant V1a antagonists, then the discovery of risdiplam, an approved drug for the treatment of spinal muscular atrophy, and finally the identification of $\gamma$-secretase modulators for the potential treatment of AD.

\section{Vasopressin 1a Antagonists}

Arginine vasopressin (AVP) is an evolutionary highly conserved 9-amino acid peptide activating $G$ protein coupled receptor (GPCR). Three vasopressin GPCRs are reported, V1a, V1b and $\mathrm{V} 2$. While $\mathrm{V} 2$ receptor is mainly expressed in the kidney playing a key role in water retention, ${ }^{[7,8]}$ both $\mathrm{V} 1 \mathrm{a}$ and $\mathrm{V} 1 \mathrm{~b}$ receptors are expressed in the rat brain limbic area, with V1a demonstrating a similar expression in human ${ }^{[9]}$ and monkey ${ }^{[10]}$ brain regions with additional cortical expression. The observations that V1a receptor has been implicated in the social behavior of voles, ${ }^{[11]}$ and the V1a gene associated with ASD, ${ }^{[12-17]}$ supported our hypothesis that a small molecule V1a antagonist could offer a treatment option for patients suffering from ASD. Such a molecule should be brain penetrant and demonstrate a selectivity versus V2, but also versus the closely related oxytocin receptor ${ }^{[18]}$ to avoid peripheral side-effect and detrimental interaction with the pro-social effects of oxytocin. ${ }^{[19]}$

At the start of our project, most of the reported V1a antagonists described were targeting peripheral indications. Therefore, to identify novel chemical matter suitable for optimization towards achieving a high selectivity and brain penetration, we decided to perform a high throughput screening (HTS). This campaign was performed using a FLIPR functional assay, followed for the confirmed hits by binding affinity determination on both human $\mathrm{V} 1 \mathrm{a}$ and $\mathrm{V} 1 \mathrm{~b}$ receptors with a scintillation proximity assay (SPA). Among the hits identified, compound $\mathbf{6}$ with binding affinities of $2830 \mathrm{nM}$ for the hV1a receptor (Fig. 3) attracted our attention due to its very high chemical tractability amenable to parallel synthesis.

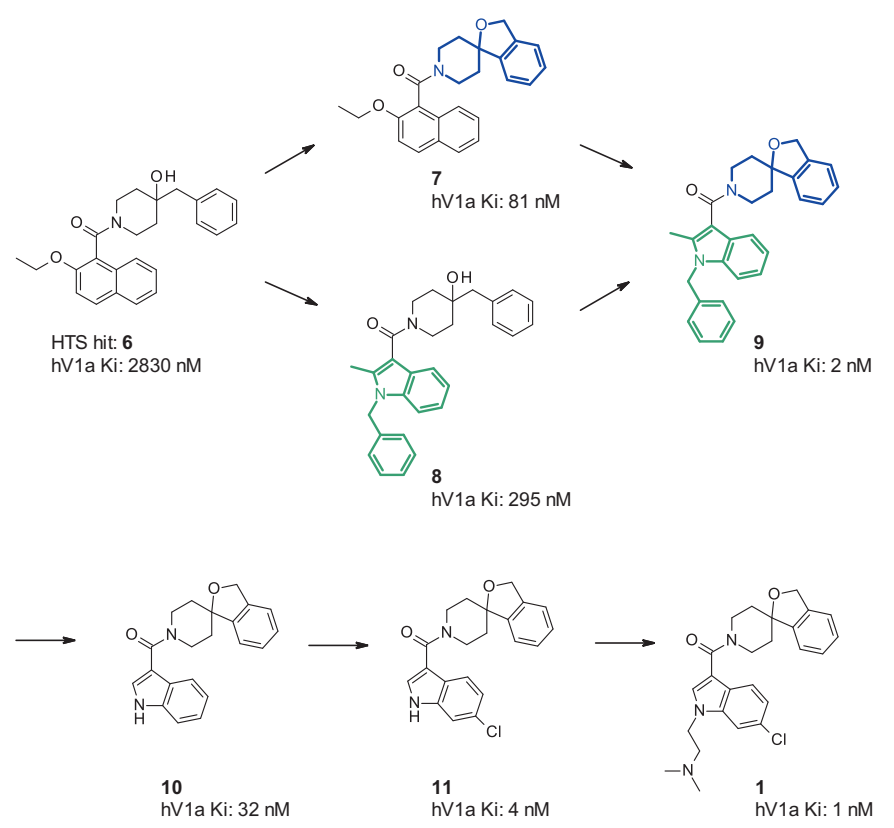

Fig. 3. Chemical optimization from HTS hit 6 to our first V1a molecule evaluated in human 1.

The strategy to optimize the in vitro potency relies on a twopronged approach, a chemogenomic-based method and an efficient chemical library generation. Chemogenomics is a powerful complementary approach to the HTS. It is based on the concept that proteins with a similar binding site should bind similar small molecules, allowing virtual screening and identification of molecules that were not part of the initial screening deck. We identified the nearest 10 GPCR neighbors of the $\mathrm{hV} 1 \mathrm{a}$ receptor, and among them, small molecule ligands were mostly known (in-house and in the literature) for the neurokinin 1 (NK1) receptor. We selected a small diverse set of NK1 antagonists (31 compounds) and tested them for hV1a affinity. Gratifyingly, compound 7 displayed a very high affinity of $81 \mathrm{nM}$ on hV1a. This compound contained an isomeric spiro-piperidine moiety in place of the 4-benzyl-4-hydroxypiperidine moiety contained in HTS hit 6 . While performing those activities, we explored the use of alternative fused biaryl systems as a replacement of the naphthalene moiety contained in compound $\mathbf{6}$. This led to the discovery of compound $\mathbf{8}$, containing an $N$-benzyl-3-indole fragment, displaying a 10 -fold improved potency as compared to HTS hit $\mathbf{6}$. The next step to combine those two fragments was straightforward, resulting in a synergistic effect on the $\mathrm{hV} 1 \mathrm{a}$ potency $(\mathrm{Ki}: 2 \mathrm{nM})$ for the corresponding compound $\mathbf{9}$, one thousand fold more potent than the hit.

Not surprisingly, compound $\mathbf{9}$ was associated with a poor aqueous solubility $(<1 \mu \mathrm{g} / \mathrm{mL}$ at $\mathrm{pH} 6.5)$ and a very high lipophilicity ( $\operatorname{LogD}$ not measurable). We hypothesized that both the benzyl and the methyl fragments present on the indole were not critical for potency. This led to the preparation of compound $\mathbf{1 0}$. Even though the absolute in vitro potency was reduced compared 
to compound 9, the ligand efficiency (LE) and the lipophilic ligand efficiency (LLE) was improved, those two parameters being excellent indicators for lead optimization. ${ }^{[20]}$ The full potency was restored upon introduction of a chlorine atom (compound 11) with an hV1a potency of $4 \mathrm{nM}$, maintaining a favorable LLE, and a better (but not satisfactory) solubility and lipophilicity as compared to compound 9. Several polar side chains were then evaluated, attached to the nitrogen atom of the indole. Looking at the overall properties impact of those fragments in terms of potency, solubility, and hP-gp transport, the $N, N$-dimethylaminoethyl side chain appears to be the optimal one leading to the discovery of compound 1, suitable for proof-of-mechanism (PoM) clinical studies in people with autism. ${ }^{[21]}$ While a full development of this compound 1 was precluded due to some suboptimal clearance in animals (preventing sufficient exposures to be reached to establish a robust safety margin), a PoM study in men with autism spectrum disorder demonstrated improvements in some exploratory biomarkers. ${ }^{[22]}$

As further optimization of the compound $\mathbf{1}$ was not feasible, we explored the replacement of the indole moiety. A scaffold hopping strategy with the triazolobenzadiazepine moiety from compound 12 (PF-184563) ${ }^{[23]}$ appeared attractive (Fig. 4), despite that $\mathbf{1 2}$ was a P-gp substrate limiting brain penetration. Both compounds 1 and 12, shared similar overlapping features, a chlorophenyl moiety and a good H-bond acceptor as a carbonyl moiety for $\mathbf{1}$ and an $\mathrm{N}$-atom of the triazole moiety for $\mathbf{1 2}$. The resulting hybrid compound $\mathbf{1 3}$ displayed a good potency for the $\mathrm{hV} 1 \mathrm{a}$ receptor. From there, an optimization and a fine tuning of the properties to deliver a compound with good oral bioavailability and CNS penetration (absence of P-gp), while achieving a very high selectivity led to the discovery of $\mathbf{2}$ (balovaptan). ${ }^{[2]}$ This compound ultimately reached phase 3 clinical trials for the potential treatment of ASD. ${ }^{[24]}$

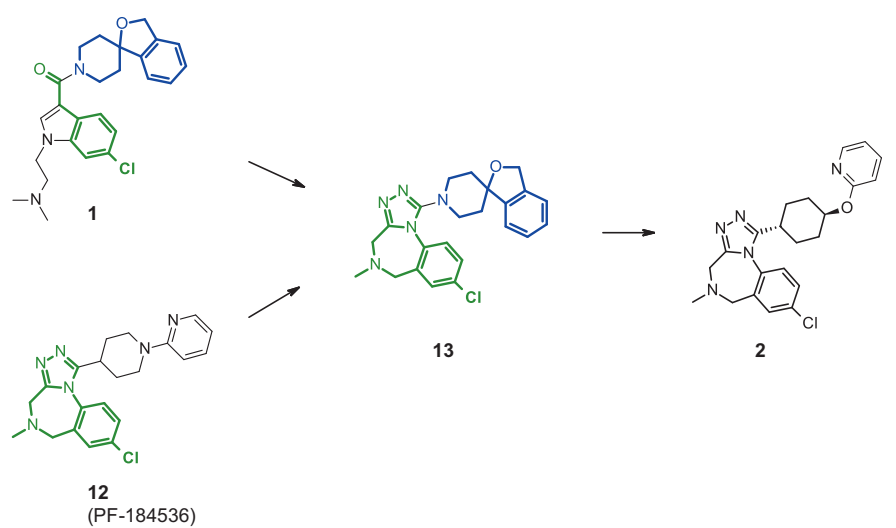

Fig. 4. Chemical optimization from compound $\mathbf{1}$ to compound 2 .

\section{Survival Motor Neuron 2 Splicing Modifier}

Untreated, spinal muscular atrophy (SMA) is the most common genetic cause of death in infants and toddlers with an incidence of roughly 1 in 6,000 to 1 in 11000 live births. ${ }^{[25-27]}$ There are three common types of SMA, displaying various degrees of severity, from type 1 (most severe form leading to death if untreated) to type 3.[28] This autosomal recessive disease is caused by mutations or deletion of the survival of motor neuron 1 (SMN1) gene which leads to loss of spinal motor neurons and skeletal muscle atrophy. The survival motor neuron (SMN) protein, product of the SMN1 gene, is crucial for normal development in all species. [29-31]

However, most humans possess a highly homologous gene named SMN2. In its coding region, this gene has a single mutation in comparison to $S M N 1$, responsible for the exclusion of exon 7 from the majority of the mRNA. This in turn produces a truncated SMN protein that is rapidly degraded. This SMA-underlying genetic characteristic has enabled our approach to treat SMA. Together with our development partners, our strategy was the identification of orally bioavailable small molecules that would shift the outcome of the alternative splicing to include $S M N 2$ exon 7 to ultimately increase functional SMN protein expression.

Furthermore, this approach has opened up new doors for medicinal chemistry.[32] While for a long time, small molecule therapeutics were considered only for interaction with proteins, it has become apparent that their target space could expand into the realm of RNAs. ${ }^{[33]}$ This is supported by the development of new numerous biophysical and screening methods on an industrial scale. This concept of RNA targeting with small molecules was validated with the approval of compound 4, (risdiplam), by the FDA in August 2020 and EMA in March 2021 as the first small molecule splicing modifier drug, as a transformative medicine for SMA.

The program started with a high throughput screening (HTS) aiming at the identification of small molecules increasing the inclusion of exon 7 during SMN2 pre-mRNA splicing. ${ }^{[34]}$ From one of the hits, compound 14 (Fig. 5), potency optimization led to the discovery of similar derivatives with three different cores. ${ }^{[35]}$ Key requirements were the introduction of a basic $N$-atom for the R1 fragment, and an $H$-bond acceptor for the R2 fragment. It then became clear that the most promising core to deliver a medicine was the pyrido-pyrimidinone core 3 , as exemplified ${ }^{[3]}$ by compound 15. Any potential development of a compound with a central core as 1 or 2 (coumarin or iso-coumarin) was hampered by a mutagenic potential, in-vitro phototoxicity liability in addition to a poor in-vitro human plasma and chemical stability. Finally, balancing in vitro potency and P-gp led us to the selection of compound $\mathbf{3}$, as the first small molecule SMN2 splicing modifier tested in humans. ${ }^{[3]}$ To expedite the discovery of $\mathbf{3}$ and its optimization versus P-gp, we used lipophilicity $(\operatorname{LogD})$ as a simple surrogate, a good correlation being observed between the measured P-gp efflux ratio and the in silico lipophilicity.

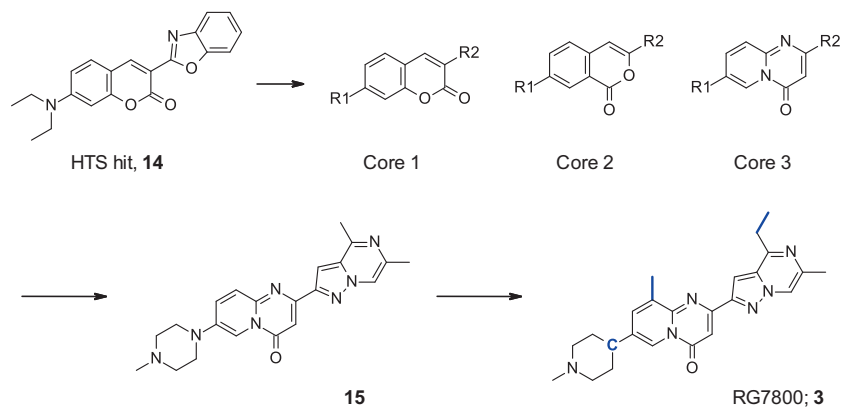

Fig 5. Discovery of compound 3, RG7800.

However, the clinical development of the compound $\mathbf{3}$ was halted as a precautionary measure due to a retinal finding observed in the long-term chronic preclinical toxicity study only at exposures in excess of those investigated in patients. We therefore looked for a superior molecule. We postulated that the high aromaticity and electronic conjugation of the fused bicyclic central cores were at least partly responsible for the liabilities associated with the cores 1 and 2 described herein above. The impact of aromatic count on compound developability has been the subject of numerous papers, with a higher number correlating with an increased risk of attrition. ${ }^{[36]}$ To reduce the number of $C$-sp ${ }^{2}$ atoms from the cores $1-3$, we decided to keep only one aromatic ring in the core and use a linker/spacer moiety (blue circle in Fig. 6, acyclic or saturated cyclic) to adequately position either the R2 
or the R1 moiety. ${ }^{[37]}$ Among the multiple options tried, the benzamide moiety displayed a first hint of potency in a micromolar range; validating the concept. The introduction of a fluorine atom on the phenyl ring to lock the putative planar active conformation through an intramolecular H-bond, led to compound $\mathbf{1 7}$ with a nearly ten-fold potency improvement. Further manipulation of the basic amine residue brings in vitro potency in a range suitable for compound 18 to display in vivo efficacy in two SMA mice models (neonatal $\Delta 7$ and adult $\mathrm{C} / \mathrm{C}$ allele mice). At this stage, we focused our attention on the identification of benzamide derivatives bearing an R2 group, from which the corresponding amino-R2 which could be generated from a hydrolysis of the amid bond, would be devoid of any potential mutagenicity. This ultimately led us to the optimal compound 19 in that series.
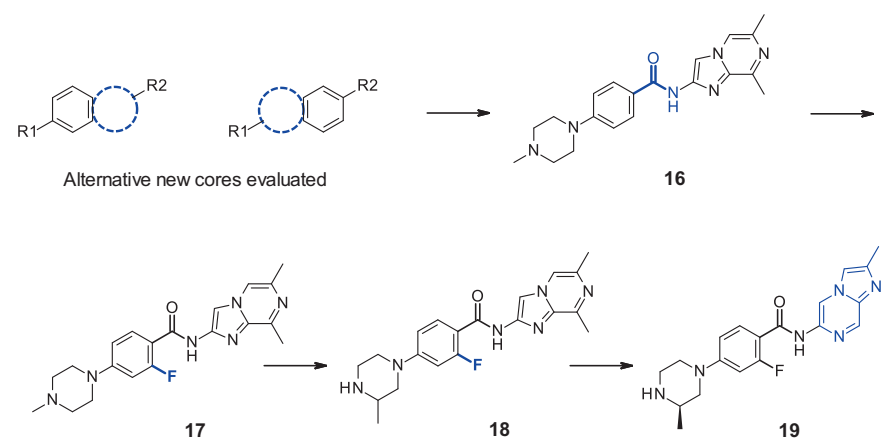

Fig 6. Discovery of a novel benzamide series.

Initially the benzamide series held some promises. However, its in vitro/in vivo efficacy remained lower than that achieved with compounds originating from the pyrido-pyrimidinone series such as our first candidate compound $\mathbf{3}$. We therefore kept this core and evaluated novel $\mathrm{R} 2$ residues to improve the $S M N 2$ potency, as a way to increase potentially therapeutic window versus non-target related side effects (Fig. 7). The use of an imidazo-pyridazine moiety led to compounds of the type $\mathbf{2 0}$ with a markedly enhanced potency. ${ }^{[4]}$ From there it remained to select the best amino moiety $\mathrm{R} 1$ to achieved the lowest basicity possible while maintaining the high potency, but also preventing the formation of a peripherally restricted active metabolite. The selected R1 moiety should also lead to a final compound with a good brain penetration and advantageous tissue distribution, for this the lipophilicity was also a key parameter. The number of R1 fragments that could be potentially introduced being extremely large, we made use of machine learning prediction. A virtual library of final compounds with commercially available amines was made, and filtered based on calculated LogD (range 1.5-3.0), pKa (6.5-8.5) and MW (< $500 \mathrm{~g} / \mathrm{mol}$ ). This ultimately led to the discovery of compound 2 , known as risdiplam, exhibiting an excellent tissue distribution, ${ }^{[38]}$ and human pharmacokinetics and pharmacodynamics. ${ }^{[39]}$

We pushed a number of scientific boundaries in the frame of this program. From RNA selectivity assessment and optimization, ${ }^{[40]}$ to in vivo efficacy evaluation, ${ }^{[41,42]}$ including diligent work on the elucidation of the mode of actions. ${ }^{[43,44]}$ Those efforts ultimately culminated with the approval of compound $\mathbf{2}$,

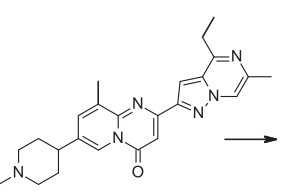

3

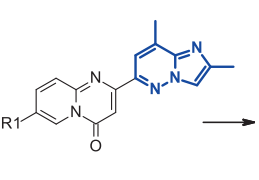

20

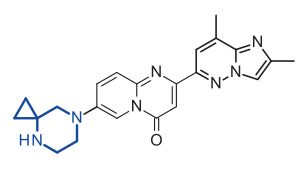

2
Fig. 7. Discovery of compound 2 , risdiplam. risdiplam, by the FDA in August 2020, as the first transformative oral treatment for spinal muscular atrophy.

\section{4. $\gamma$-Secretase Modulators}

Since 1990, there has been a dramatic increase in the number of people living with Alzheimer's disease (AD) and other forms of dementia, with a current estimate of around 50 million people affected, mainly due to ageing and population growth. ${ }^{[45]} \mathrm{By}$ 2050 , this number is expected to triple and could be well over 150 million. ${ }^{[46]}$ The unmet need is huge as currently there is no approved disease modifying therapy. AD comprises a continuum of progressive neurodegenerative pathologies associated with cognitive, functional and behavioral deficits. Early stage of $\mathrm{AD}$ are characterized by the accumulation of $\mathrm{A} \beta$ plaques and tau pathologies. These microscopic changes lead to synaptic dysfunction and the subsequent loss of synapses and neuronal death. The disease progression is marked by the accumulation of $\mathrm{A} \beta$ in the cortex (excess production or reduced clearance) and the aggregation of pathological tau protein to form neurofibrillary tangles, with amyloid deposits appearing first. ${ }^{[47,48]}$ These pathologies signal the progression from preclinical $A D$ to $A D$ dementia. The typical AD disease course may take 25 years from pre-symptomatic stages to symptom onset. [49]

Preventing the formation of amyloid plaques appears to be an appealing therapeutic approach. Modulating $\gamma$-secretase represents a very attractive approach to reduce neurotoxic $A \beta 42$, the main constituent of amyloid plaques, by shifting the cleavage to form smaller, more soluble $\mathrm{A} \beta$ peptides. These shorter $\mathrm{A} \beta$ peptides do not lead to the formation of toxic aggregates, while potentially even inhibiting the aggregation of the A $\beta 42$ in-vitro. ${ }^{[50]}$ These aspects explain why a number of GSMs, including our own contribution, were reported.[51]

We have reported the discovery of compounds of the type 21 (Fig. 8) a decade ago, ${ }^{[52]}$ and shortly afterwards, the advantageous replacement of the phenyl linker by a saturated bridge piperidine leading to derivatives of the type 22. ${ }^{[53]}$ The molecules 22 being associated with in vitro phototoxicity, further reduction of the aromaticity was required. A first approach was the replacement of the peripheral phenyl moiety by alkoxy fragments leading to derivatives 23. ${ }^{[54]}$ While this modification suppressed this flag, none of the derivatives from this class was suitable for further advancement, mostly hampered by a suboptimal potency. ${ }^{[5]}$ We next turned our attention on the central core, the triazolopyridine. Multiple saturated systems, with ring sizes ranging from five to seven atoms and with either an $N$ or $C$-atom in benzylic position were evaluated providing compounds 24. Among them, the triazoloazepine core as for compounds 25 (Fig. 8) gave the highest in vitro potency. The ring size effect was rationalized based on 3D modeling activities, displaying a profound effect on the phenyl moiety position. In the case of the seven ring system (with a $C$-atom in benzylic position), the phenyl remained closely positioned as compared to its initial position. A fine-tuning of the phenyl substitution pattern indicated a trifluoro-phenyl as the optimal substituent (compounds 25). Finally, the selection of the head group (HG) moiety was made to balance a number of properties as the potency, solubility, clearance and P-gp, culminating in the discovery of our clinical candidate molecule 5. ${ }^{[5]}$

As depicted in Fig. 8, optimization from compound $\mathbf{2 1}$ to 22 was the result of a phenyl spacer replacement by an advantageous bridge piperidine (BP) moiety. We therefore aimed at establishing a broad and full comparison between the phenyl and BP fragments, but also with the bicyclo[1.1.1]pentane (BCP) and bicyclo[2.2.2.] octane (BCO) which are nowadays seen as standard saturated phenyl bioisosteres (Fig. 9, panel A). For this purpose, we incorporated these four spacers in three different GSM series (Fig. 9, panel B), and evaluated beside the in vitro potency, key physicochemical properties like solubility and lipophilicity. 


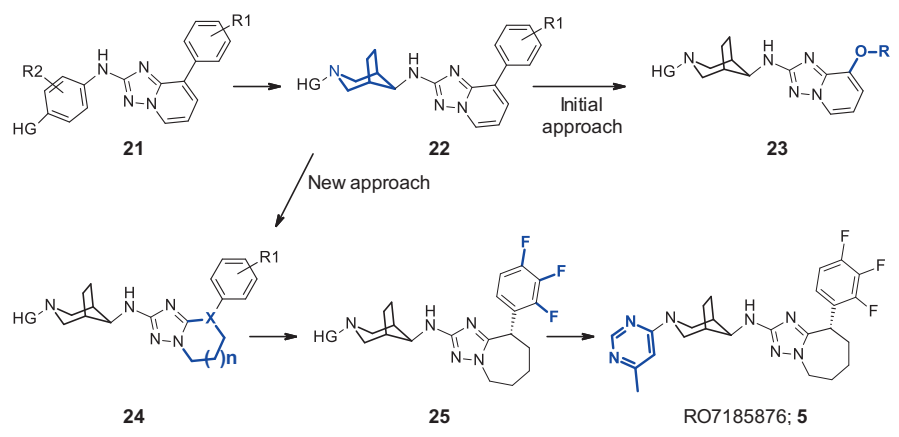

Fig. 8. Discovery pathway leading to compound $\mathbf{5}$.

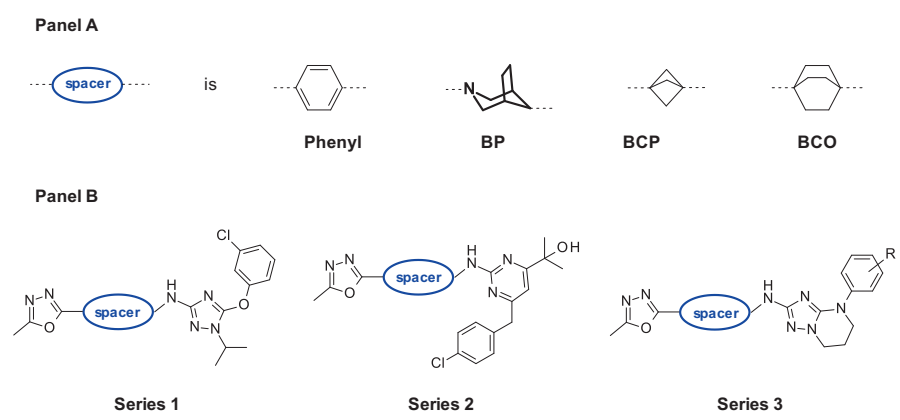

Fig. 9. Panel A: Phenyl bioisosteres. Panel B: Three series considered to enable a comparison

Across these different series, the bridge piperidine (BP) performed the best in terms of in vitro potency. Very interestingly, this BP fragment was also the best in terms of solubility and lipophilicity compared to the phenyl, BCP and BCO moieties.[6] Those data demonstrated that the BP fragment would find its space in the arsenal of medicinal chemists in the quest of drug-like properties improvement, replacing advantageously phenyl moieties when not involved in any productive $\pi-\pi$ interactions.

\section{Conclusion}

Medicinal chemistry plays a central role in drug discovery. In this article, we described our contribution to the discovery of several very promising molecules to address severe unmet medical needs. Among them, risdiplam, was recently approved (as Evrysdi) by both the FDA and the EMA for the treatment of patient for the treatment of spinal muscular atrophy in adults and children 2 months of age and older.

\section{Acknowledgments}

We would like to thank all patients participating in clinical trials and all our colleagues at F. Hoffmann-La Roche. In addition, we would like to thank our colleagues at the SMA Foundation and PTC Therapeutics for the excellent work performed in collaboration in the SMN project.

Received: May 31, 2021

[1] H. Ratni, M. Rogers-Evans, C. Bissantz, C. Grundschober, J.-L. Moreau, F. Schuler, H. Fischer, R. Alvarez Sanchez, P. Schnider, J. Med. Chem. 2015, 58, 2275, https://doi.org/10.1021/jm501745f.

[2] P. Schnider, C. Bissantz, A. Bruns, C. Dolente, E. Goetschi, R. Jakob-Roetne, B. Kunnecke, T. Mueggler, W. Muster, N. Parrott, E. Pinard, H. Ratni, C. Risterucci, M. Rogers-Evans, M. von Kienlin, C. Grundschober, J. Med. Chem. 2020, 63, 1511, https://doi.org/10.1021/acs.jmedchem.9b01478.

[3] H. Ratni, G. M. Karp, M. Weetall, N. A. Naryshkin, S. V. Paushkin, K. S. Chen, K. D. McCarthy, H. Qi, A. Turpoff, M. G. Woll, X Zhang, N. Zhang, T. Yang, A. Dakka, P. Vazirani, X. Zhao, E.
Pinard, L. Green, P. David-Pierson, D. Tuerck, A. Poirier, W. Muster, S. Kirchner, L. Mueller, I. Gerlach, F. Metzger, J. Med. Chem. 2016, 59, 6086, https://doi.org/10.1021/acs.jmedchem.6b00459.

[4] H. Ratni, M. Ebeling, J. Baird, S. Bendels, J. Bylund, K. S. Chen, N. Denk, Z. Feng, L. Green, M. Guerard, P. Jablonski, B. Jacobsen, O. Khwaja, H. Kletzl, C.-P. Ko, S. Kustermann, A. Marquet, F. Metzger, B. Mueller, N. A. Naryshkin, S. V. Paushkin, E. Pinard, A. Poirier, M. Reutlinger, M. Weetall, A. Zeller, X. Zhao, L. Mueller, J. Med. Chem. 2018, 61, 6501, https://doi.org/10.1021/acs.jmedchem.8b00741.

[5] H.Ratni,A.Alker,B.Bartels, C. Bissantz,W.Chen,I.Gerlach,A.Limberg,M.Lu, W.Neidhart, S. Pichereau, M. Reutlinger, R.-M. Rodriguez-Sarmiento, R. JakobRoetne, G.Schmitt,E.Zhang, K. Baumann,ACSMed.Chem.Lett. 2020,11,1257, https://doi.org/10.1021/acsmedchemlett.0c00109.

[6] H. Ratni, K. Baumann, P. Bellotti, X. A. Cook, L. G. Green, T. Luebbers, M. Reutlinger, A. F. Stepan, W. Vifian, RSC Med. Chem, 2021, 12, 758, https://doi.org/10.1039/D1MD00043H.

[7] N. L. Ostrowski, S. J. Lolait, D. J. Bradley, A. M. O'Carroll, M J. Brownstein, W. S. Young, III, Endocrinol. 1992, 131, 533, https://doi.org/10.1210/en.131.1.533.

[8] M. Birnbaumer, Trends Endocrinol. Metab. 2000, 11, 406 , https://doi.org/10.1016/s1043-2760(00)00304-0.

[9] F. Loup, E. Tribollet, M. Dubois-Dauphin, J. J. Dreifuss, Brain Research 1991, 555, 220, https://doi.org/10.1016/0006-8993(91)90345-v.

[10] L. J. Young, D. Toloczko, T. R. Insel, J. Neuroendocrinol. 1999, 11, 291, https://doi.org/10.1046/j.1365-2826.1999.00332.x.

[11] E. A. D. Hammock, L. J. Young, Phil. Trans. Royal Soc. B 2006, 361, 2187, https://doi.org/10.1098/rstb.2006.1939.

[12] S. J. Kim, L. J. Young, D. Gonen, J. Veenstra-VanderWeele, R. Courchesne, E. Courchesne, C. Lord, B. L. Leventhal, E. H. Cook, Jr.; T. R. Insel, Mol. Psychiatry 2002, 7, 503, https://doi.org/10.1038/sj.mp.4001125.

[13] T. H. Wassink, J. Piven, V. J. Vieland, J. Pietila, R. J. Goedken, S. E. Folstein, V. C. Sheffield, Mol. Psychiatry 2004, 9, 968 , https://doi.org/10.1038/sj.mp.4001503.

[14] N. Yirmiya, C. Rosenberg, S. Levi, S. Salomon, C. Shulman, L. Nemanov, C. Dina, R. P. Ebstein, Mol. Psychiatry 2006, 11, 488, https://doi.org/10.1038/sj.mp.4001812.

[15] S. Y. Yang, S.-C. Cho, H. J. Yoo, I. H. Cho, M. Park, B.-N. Kim, J.W. Kim, M.-S. Shin, T.-W. Park, J.-W. Son, U.-S. Chung, H.-W. Kim, Y.-H. Yang, J.-O. Kang, S. A. Kim, Neurosci. Lett. 2010, 479, 197 , https://doi.org/10.1016/j.neulet.2010.05.050.

[16] K. E. Tansey, M. J. Hill, L. E. Cochrane, M. Gill, R. J. L. Anney, L. Gallagher, Mol. Autism 2011, 2, 3, https://doi.org/10.1186/2040-2392-2-3.

[17] S. Y. Yang, S. A. Kim, G. M. Hur, M. Park, J.E. Park, H. J. Yoo, Mol. Autism 2017, 8, 44/1-44/10, https://doi.org/10.1186/s13229-017-0161-9.

[18] T. Kimura, O. Tanizawa, K. Mori, M. J. Brownstein, H. Okayama, Nature 1992, 356, 526, https://doi.org/10.1038/356526a0.

$\begin{array}{llllll}\text { [19] T. R. Insel, Neuron } & \mathbf{2 0 1 0}, \quad 65, & 768,\end{array}$ https://doi.org/10.1016/j.neuron.2010.03.005.

[20] A. L. Hopkins, G. M. Keserue, P. D. Leeson, D. C. Rees, C. H. Reynolds, Nat. Rev. Drug Discov. 2014, 13, 105, https://doi.org/10.1038/nrd4163.

[21] A study of RO5028442 in adult male high-functioning autistic patients. http:// clinicaltrials.gov/ct2/show/NCT01474278.

[22] D. Umbricht, M. del Valle Rubido, E. Hollander, J. T. McCracken, F. Shic, L. Scahill, J. Noeldeke, L. Boak, O. Khwaja, L. Squassante, C. Grundschober, H. Kletzl, P. Fontoura, Neuropsychopharmacol. 2017, 42, 1914, https://doi.org/10.1038/npp.2016.232.

[23] P. S. Johnson, T. Ryckmans, J. Bryans, D. M. Beal, K. N. Dack, N. Feeder, A. Harrison, M. Lewis, H. J. Mason, J. Mills, J. Newman, C. Pasquinet, D. J. Rawson, L. R. Roberts, R. Russell, D. Spark, A. Stobie, T. J. Underwood, R. Ward, S. Wheeler, Bioorg. Med. Chem. Lett. 2011, 21, 5684, https://doi.org/10.1016/j.bmcl.2011.08.038.

[24] ClinicalTrials.gov. 'A Study to Investigate the Efficacy and Safety of RO5285119 in Participants With Autism Spectrum Disorder (ASD)', https:// www.clinicaltrials.gov/ct2/show/NCT02901431.

[25] Classification of spinal muscular atrophies. FIELD Authors: J. Pearn, Lancet 1980, 1, 919, https://doi.org/10.1016/s0140-6736(80)90847-8.

[26] T. O. Crawford, C. A. Pardo, Neurobiol. Dis. 1996, 3, 97 , https://doi.org/10.1006/nbdi.1996.0010.

[27] E. A. Sugarman, N. Nagan, H. Zhu, V. R. Akmaev, Z. Zhou, E. M. Rohlfs, K. Flynn, B. C. Hendrickson, T. Scholl, D. A. Sirko-Osadsa, B. A. Allitto, Eur. J. Hum. Genet. 2012, 20, 27, https://doi.org/10.1038/ejhg.2011.134.

[28] S. J. Kolb, J. T. Kissel, Arch. Neurol. 2011, 68, 979, https://doi.org/10.1001/archneurol.2011.74.

[29] C. Fallini, G. J. Bassell, W. Rossoll, Brain Res. 2012, 1462, 81, https://doi.org/10.1016/j.brainres.2012.01.044. 
[30] B. Schrank, R. Gotz, J. M. Gunnersen, J. M. Ure, K. V. Toyka, A G. Smith, M. Sendtner, Proc. Natl. Acad. Sci. USA 1997, 94, 9920, https://doi.org/10.1073/pnas.94.18.9920.

[31] S. Paushkin, A. K. Gubitz, S. Massenet, G. Dreyfuss, Curr. Opin. Cell Biol. 2002, 14, 305, https://doi.org/10.1016/s0955-0674(02)00332-0.

[32] H. Ratni, R. S. Scalco, A. H. Stephan, ACS Med. Chem. Lett. 2021, 12, 874, https://doi.org/10.1021/acsmedchemlett.0c00659.

[33] K. D. Warner, C. E. Hajdin, K. M. Weeks, Nat. Rev. Drug Discov. 2018, 17, 547, https://doi.org/10.1038/nrd.2018.93.

[34] N. A. Naryshkin, M. Weetall, A. Dakka, J. Narasimhan, X. Zhao, Z. Feng, K. K. Y. Ling, G. M. Karp, H. Qi, M. G. Woll, G. Chen, N. Zhang, V. Gabbeta, P. Vazirani, A. Bhattacharyya, B. Furia, N. Risher, J. Sheedy, R. Kong, J. Ma, A. Turpoff, C.-S. Lee, X. Zhang, Y.-C. Moon, P. Trifillis, E. M. Welch, J. M. Colacino, J. Babiak, N. G. Almstead, S. W. Peltz, L. A. Eng, K. S. Chen, J. L. Mull, M. S. Lynes, L. L. Rubin, P. Fontoura, L. Santarelli, D. Haehnke, K. D. McCarthy, R. Schmucki, M. Ebeling, M. Sivaramakrishnan, C.-P. Ko, S. V. Paushkin, H. Ratni, I. Gerlach, A. Ghosh, F. Metzger, Science 2014, 345, 688, https://doi.org/10.1126/science.1250127.

[35] M. G. Woll, H. Qi, A. Turpoff, N. Zhang, X. Zhang, G. Chen, C. Li, S Huang, T. Yang, Y.-C. Moon, C.-S. Lee, S. Choi, N. G. Almstead, N. A. Naryshkin, A. Dakka, J. Narasimhan, V. Gabbeta, E. Welch, X. Zhao, N. Risher, J. Sheedy, M. Weetall, G. M. Karp, J. Med. Chem. 2016, 59, 6070, https://doi.org/10.1021/acs.jmedchem.6b00460.

[36] T. J. Ritchie, S. J. F. MacDonald, Drug Discov. Today 2009, 14, 1011, https://doi.org/10.1016/j.drudis.2010.11.014.

[37] E. Pinard, L. Green, M. Reutlinger, M. Weetall, N. A. Naryshkin, J. Baird, K. S. Chen, S. V. Paushkin, F. Metzger, H. Ratni, J. Med. Chem. 2017, 60, 4444, https://doi.org/10.1021/acs.jmedchem.7b00406.

[38] A. Poirier, M. Weetall, K. Heinig, F. Bucheli, K. Schoenlein, J. Alsenz, S. Bassett, M. Ullah, C. Senn, H. Ratni, N. Naryshkin, S. Paushkin, L. Mueller, Pharmacol. Res. Perspect. 2018, 6, e00447/1, https://doi.org/10.1002/prp2.447.

[39] S. Sturm, A. Guenther, B. Jaber, P. Jordan, N. Al Kotbi, N. Parkar, Y. Cleary, N. Frances, T. Bergauer, K. Heinig, H. Kletzl, A. Marquet, H. Ratni, A. Poirier, L. Mueller, C. Czech, O. Khwaja, Br. J. Clin. Pharmacol. 2019, 85, 181, https://doi.org/10.1111/bcp.13786.

[40] H. Ratni, L. Mueller, M. Ebeling, Prog. Med. Chem. 2019, 58, 119, https://doi.org/10.1016/bs.pmch.2018.12.003

[41] X. Zhao, Z. Feng, K. K. Y. Ling, A. Mollin, J. Sheedy, S. Yeh, J. Petruska, J. Narasimhan, A. Dakka, E. M. Welch, G. Karp, K. S. Chen, F. Metzger, H. Ratni, F. Lotti, S. Tisdale, N. A. Naryshkin, L. Pellizzoni, S. Paushkin, C.-P. Ko, M. Weetall, Hum. Mol. Genet. 2016, 25, 1885, https://doi.org/10.1093/hmg/ddw062.

[42] Z. Feng, K. K. Y. Ling, X. Zhao, C. Zhou, G. Karp, E. M. Welch, N. Naryshkin, H. Ratni, K. S. Chen, F. Metzger, S. Paushkin, M. Weetall, C.-P. Ko, Hum. Mol. Genet. 2016, 25, 964, https://doi.org/10.1093/hmg/ddv629.

[43] S. Campagne, S. Boigner, S. Rudisser, A. Moursy, L. Gillioz, A. Knorlein, J. Hall, H. Ratni, A. Clery, F. H. T. Allain, Nat. Chem. Biol. 2019, 15, 1191, https://doi.org/10.1038/s41589-019-0384-5.

[44] M. Sivaramakrishnan, K. D. McCarthy, S. Campagne, S. Huber, S. Meier, A. Augustin, T. Heckel, H. Meistermann, M. N. Hug, P. Birrer,
A. Moursy, S. Khawaja, R. Schmucki, N. Berntenis, N. Giroud, S. Golling, M. Tzouros, B. Banfai, G. Duran-Pacheco, J. Lamerz, Y. Hsiu Liu, T. Luebbers, H. Ratni, M. Ebeling, A. Clery, S. Paushkin, A. R. Krainer, F. H. T. Allain, F. Metzger, Nat. Commun. 2017, 8, 1, https://doi.org/10.1038/s41467-017-01559-4.

[45] 'Global, regional, and national burden of Alzheimer's disease and other dementias, 1990-2016: a systematic analysis for the Global Burden of Disease Study 2016', FIELD Authors, Lancet Neurol. 2019, 18, 88 , https://doi.org/10.1016/S1474-4422(18)30499-X.

[46] World Health Organisation. Dementia factsheet 2019 https://www.who.int/news-room/fact-sheets/detail/dementia

[47] C. R. Jack, Jr., D. S. Knopman, W. J. Jagust, L. M. Shaw, P. S. Aisen, W. M. Weiner, R. C. Petersen, J. Q. Trojanowski, Lancet Neurol. 2010, 9, 119, https://doi.org/10.1016/S1474-4422(09)70299-6.

[48] C. R. Jack, D. S. Knopman, W. J. Jagust, R. C. Petersen, M. W. Weiner, P. S. Aisen, L. M. Shaw, P. Vemuri, H. J. Wiste, S. D. Weigand, T. G. Lesnick, V. S. Pankratz, M. C. Donohue, J. Q. Trojanowski, Lancet Neurol. 2013, 12, 207, https://doi.org/10.1016/S1474-4422(12)70291-0.

[49] R. J. Bateman, C. Xiong, T. L. S. Benzinger, A. M. Fagan, A. Goate, N. C. Fox, D. S. Marcus, N. J. Cairns, X. Xie, T. M. Blazey, D. M. Holtzman, A Santacruz, V. Buckles, A. Oliver, K. Moulder, P. S. Aisen, B. Ghetti, W. E. Klunk, E. McDade, R. N. Martins, C. L. Masters, R. Mayeux, J. M. Ringman, M. N. Rossor, P. R. Schofield, R. A. Sperling, S. Salloway, J. C. Morris, N. Engl. J. Med. 2012, 367, 795, https://doi.org/10.1056/NEJMoa1202753.

[50] J.-F. Blain, M. G. Bursavich, E. A. Freeman, L. A. Hrdlicka, H. E. Hodgdon, T. Chen, D. E. Costa, B. A. Harrison, S. Kapadnis, D. A. Murphy, S. Nolan, Z. Tu, C. Tang, D. A. Burnett, H. Patzke, G. Koenig, Alzheimer's Res. Ther 2016, 8, 34, https://doi.org/10.1186/s13195-016-0199-5.

[51] M. G. Bursavich, B. A. Harrison, J.-F. Blain, J. Med. Chem. 2016, 59, 7389, https://doi.org/10.1021/acs.jmedchem.5b01960.

[52] K. Baumann, E. Goetschi, L. Green, S. Jolidon, H. Knust, A. Limberg, T Luebbers, A. Thomas, 2011-EP511842011092272, $20110128,2011$.

[53] K. Baumann, L. Green, A. Limberg, T. Luebbers, A. Thomas, 2012 EP533012012116965, 20120228, 2012.

[54] R. M. Rodriguez Sarmiento, C. Bissantz, J. Bylund, A. Limberg, W. Neidhart, R. Jakob-Roetne, L. Wang, K. Baumann, J. Med. Chem. 2020, 63, 8534, https://doi.org/10.1021/acs.jmedchem.0c00909.

\section{License and Terms}

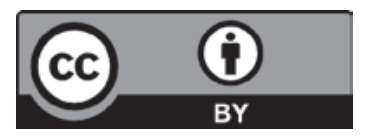

This is an Open Access article under the terms of the Creative Commons Attribution License CC BY 4.0. The material may not be used for commercial purposes.

The license is subject to the CHIMIA terms and conditions: (http:// chimia.ch/component/sppagebuilder/?view=page \&id=12).

The definitive version of this article is the electronic one that can be found at https://doi.org/10.2533/chimia.2021.614 